\title{
Movimento Não Pago: uma leitura sobre a emergência e as condições de representação da causa do transporte público na cidade de Aracaju/SE
}

ADRIELMA SANTOS

\section{Introdução}

O presente artigo examina a emergência e as condições de representação do Movimento Não Pago em torno das reivindicações no âmbito do transporte público na cidade de Aracaju/SE entre o período de 2011 a 2013. O mesmo é resultado de uma pesquisa monográfica sobre a emergência e as condições de representação desse movimento na cidade de Aracaju/SE (Santos 2014). Com base nessa pesquisa, percebe-se que a emergência do Movimento Não Pago está diretamente ligada aos eventos de protestos organizados, sobretudo pelos trabalhadores, pela juventude e o movimento estudantil universitário (Santos 2014; Oliveira; Santos 2015), em que a causa do transporte público fazia parte da sua agenda de reivindicação antes mesmo dos anos 2000, como se pode observar nesse fragmento de um jornal de circulação local da cidade de Aracaju do ano de 1983:

No documento entregue há dias passados ao governador do Estado, João Alves Filho, os estudantes estão reivindicando meia passagem para a classe estudantil, passe para os desempregados, redução das tarifas do ônibus, criação de uma empresa pelo setor público, ampliação das linhas de ônibus que servem ao Campus Universitário da UFS e melhor atendimento por parte das concessionárias (Siqueira 1983: 3).

Observa-se a partir do fragmento acima que a questão do transporte público no estado integrava a participação de algumas categorias da sociedade, como a dos estudantes, dos trabalhadores, dos desempregados, e também de políticos que apoiavam as reivindicações dos estudantes. Nesse sentido, é válido ressaltar que a Comissão que defendia esta demanda no ano de 1983 era formada pelo Presiden- 
te do DCE da Universidade Federal de Sergipe (UFS), Edvaldo Nogueira, o representante do Partido dos Trabalhadores, Marcelo Bonfim, Vereador Bosco Mendonça e o deputado estadual Nelson Araújo (Siqueira 1983). Uma das observações que aqui se faz é de que nas décadas de 80 e 90, a partir dos registros analisados (jornais impressos e eletrônicos, relatos, entrevistas, etc.), não se observou um movimento organizado e sistemático em defesa da causa do transporte público que possa configurar um movimento social no estado de Sergipe. Contudo, se tomamos outras regiões do país como São Paulo e Rio de Janeiro, destacam-se as manifestações dos quebra-quebras de trens no período entre 1976-1982, como salienta Gohn (2011) e Moisés (1985). Do mesmo modo, foi possível encontrar formas alternativas de ação vinculadas ao transporte na década de 90, como é o caso das mobilizações dos "perueiros" como um meio de transporte alternativo, e no sistema de cargas pesadas, a ação dos "caminhoneiros" (Gohn 2011; Santos; Oliveira 2015).

Por outro lado, a partir dos anos 2000, pode-se observar uma maior diversificação e organização dos trabalhadores, da juventude e do movimento estudantil em defesa dessa demanda na cidade de Aracaju, quando, por exemplo, o Movimento Passe Livre passa a se articular no estado no ano de 2003. Já em 2010, forma-se uma Frente em Defesa do Transporte Público e da Mobilidade Urbana, em 2011 o surgimento do Movimento Não Pago e em 2013 os Acorda Aracaju ${ }^{1}$, que ao longo do artigo compreender-se-á a importância desses acontecimentos para o surgimento e representação do Movimento Não Pago.

Ressalta-se ainda que a diversificação e organização de vários atores sociais se mobilizando em torno da causa do transporte público, a partir dos anos 2000 na cidade de Aracaju, se relacionam a um conjunto de manifestações que passaram a ocorrer em todas as regiões do país nesse período. Nesse sentido, foram publicados livros,artigos e coletâneas que exploram de forma mais geral o assunto, principalmente depois das manifestações de junho de 2013. Dentre esse conjunto de publicações destacam-se a coletânea Cidades Rebeldes (Maricato et. al. 2013) produzida e editada entre junho e julho de 2013, o livro Vinte Centavos (Judensnaider et. al. 2013), foca principalmente na trajetória do MPL, o artigo A Sociedade Brasileira em Movimento (Gohn 2014) teve como objetivo pensar as especificidades e novidades presentes nas manifestações de junho de 2013, comparando com outras manifestações como as Diretas Já (1984) e com o Fora Collor (1992) e \#vemprarua (Silva 2014), questiona a utilização das tecnologias de informação e comunicação como novas formas dos atores contestarem. Esses trabalhos trazem questionamentos significativos para pensar as manifestações de junho de 2013, alguns ressaltando principalmente um caráter espontâneo das manifestações, outros um caráter mais processual e relacional.

Esse artigo busca compreender o processo de emergência e representação do Não Pago na cidade de Aracaju, dentro da abordagem de processos políticos, redes sociais e identidade (Clemens 2010; Cefaï 2009; Mische 1996; 1997; 2008; Oliveira 2010; Tilly 2010). Nesse sentido, a partir da aborda-

1 Os Acordas Aracaju foram manifestações que ocorreram durante junho e julho de 2013 e tinha como pauta inicial a diminuição da tarifa do transporte público, período que também ocorria manifestações em várias cidades do país. Nos três primeiros eventos, houve a adesão da população o Movimento Não Pago era o principal organizador e porta-voz dos atos, nos dois últimos Acorda Aracaju vários outros movimentos sociais, centrais sindicais, coletivos e partidos públicos, começaram a organizar o evento e o Não Pago começou a perder espaço como protagonista dos Acordas. Os atos ocorreram nas seguintes datas: o $1^{\circ}$ Acorda Aracaju ocorreu 20/06/2013, o $2^{\circ}$ Acorda Aracaju ocorreu em 25/06/2013, $3^{\circ}$ Acorda Aracaju 27/06/2013, 4 Acorda Aracaju 02/07/2013 e o $5^{\circ}$ Acorda Aracaju 11/07/2013. 
gem de processos políticos de Charles Tilly, todo movimento social é antes de tudo uma ação política estruturada. Tilly (2010) considera que um movimento social surge a partir de interesses particulares dos atores, das articulações desses atores com outros atores políticos, como também a partir mudanças no contexto político. Segundo Tilly não se pode utilizar o termo manifestação como sinônimo de movimento social, pois as manifestações fazem parte de um ciclo de protestos que pode ser apenas esporádico, além disso, outros dois aspectos ressaltados pelo autor é que a rede de apoiadores não pode ser considerada o movimento em si e ao mesmo tempo não pode analisar o movimento social como singular, unitário, mas deve analisá-lo interligando-o a outros âmbitos da sociedade (Tilly 2010). De acordo com isso, o autor enfatiza que a análise do surgimento de um movimento social não deve ser considerada apenas como atitudes e interesses de uma condição social, mas como algo que tem grande relevância no processo histórico mais longo e amplo. Nesse sentido, o presente artigo entende por movimentos sociais como sendo "um conjunto particular, interconectado, em evolução e histórico de interações e práticas. Refere-se à combinação característica de campanha, repertório e demonstração de VUNC”2 (Tilly 2010: 142).

Por outro lado, é preciso considerar também a perspectiva de Daniel Cefaï (2009), quando o autor acredita que a organização e formação de um movimento social envolvem a mobilização de um conjunto de recursos por parte dos atores sociais que o compóe. Tendo em vista que para o autor estes recursos são tanto materiais quanto imateriais, a respeito disso ele defende o seguinte:

São agenciamentos de objetos, normas e pessoas que ordenam o que os membros podem fazer ver ou dizer. Elas constituem conjunturas prático-sensíveis, que fixam hábitos de cooperação e de conflito e que fornecem parâmetros de experiência cognitiva e normativa (Cefaï 2009:19).

Em consonância com isso, Cefaï (2009) fala dos "repertórios de formas organizacionais disponíveis”. Estes repertórios consistem na circulação de informações, de repartição de poderes, divisão de tarefas, de cooperação entre operadoras, de distribuição de direitos e concentração de decisões. No entanto, este repertório é muito evidente e deixa claro o que está acontecendo nos "bastidores". Para Cefaï (idem), a análise das redes sociais do movimento é fundamental para compreender como ele surge, mobiliza os recursos e se representa. Outra análise que dialoga com a de Cefaï sobre repertórios organizacionais é a de Clemens (2010). A autora entende por repertórios organizacionais o conjunto de modelos organizacionais e empiricamente disponíveis (idem: 165) que podem ser mobilizados pelos atores políticos. Neste sentido, Clemens entende que o mundo social oferece múltiplos modelos de organização, bem como relativas convenções a quem pode se utilizar de quais modelos para quais propósitos (idem: 164). A autora salienta, portanto que:

Os modelos de organização compreendem tanto padrões para os arranjos de relações no interior de uma organização como conjuntos de roteiros para a ação culturalmente associados com esse tipo de organização. Dessa forma, os modelos podem ser pensados como sendo intermediários entre dimensões abstratas de uma forma de organização (por exemplo, grau de hierarquia) e exemplos de organizações específicas. Modelos podem referir-se a "organizações de um determinado tipo" ou a "organizações que fazem determinado tipo de coisa". A menção, quer a um atributo

2 Para saber mais sobre Valor, Unidade, Números e Comprometimentos, ver em Tilly (2010). 
quer a uma ação, pode evocar um modelo compartilhado ou uma forma de organizar (Clemens 2010: 164).

Essa noção de repertórios organizacionais é pertinente para analisar a emergência e representação do Movimento Não Pago, justamente pelo fato dela permitir uma análise de como os modelos de organização podem variar no tempo, por conta das mudanças que ocorrem não só no contexto político, socioeconômico e cultural, mas também leva em consideração a atuação dos atores que estão mobilizando esses repertórios disponíveis. Assim, Clemens (2010) não focaliza nas formas institucionalizadas de organização, mas nas estratégias de organização que mobilizam múltiplos modelos de organização, que são mais ou menos institucionalizados. Na perspectiva de Cefaï (2009) e Clemens (2010), portanto, é fundamental analisar as redes sociais, os recursos mobilizados e as experiências dos atores para compreender como surge e como um movimento social se organiza. Essa perspectiva é interessante para analisar o movimento estudado neste trabalho, uma vez em que parte da análise das experiências dos atores que integram o movimento, ao mesmo tempo que permite analisar as "pessoas-pontes" que mediam as ações desses atores na defesa do transporte público e gratuito.

Considerando essas perspectivas teóricas sobre a formação de um movimento social, redes sociais e repertórios organizacionais, o artigo está organizado a partir de dois argumentos principais que permitem compreender a emergência e as formas de representação do Movimento Não Pago na cidade de Aracaju. $\mathrm{O}$ argumento defendido é que a emergência e a representação do Movimento Não Pago na cidade de Aracaju no ano de 2011 estão relacionadas com os interesses particulares das suas lideranças e de seus atributos pessoais, bem como a partir da articulação dessas lideranças com outros atores políticos que sustentaram a sua ação por meio de recursos externos; Já o segundo é de que as redes sociais, os repertórios organizacionais preexistentes e as experiências pessoais das lideranças do movimento implicaram em formas de ação e organização diferenciadas que permitiram a emergência, consolidação e continuidade do movimento.

Assim, a metodologia utilizada para dar conta da defesa de tais argumentos consistiu, primeiramente, na análise dos movimentos sociais na cidade de Aracaju, que reivindicavam a causa do transporte público desde os anos 2000 e que, em certa medida, configuraram recursos materiais, humanos, simbólicos e militantes, bem como oportunidades políticas para novos atores políticos se manifestarem em torno da construção da causa do transporte público no estado de Sergipe. Para isso, investigou-se as transformações nas formas de participação política da juventude brasileira nas últimas décadas (Abramo; Branco 2005; Borelli; Oliveira 2010; Mesquita 2003; Mische 2008) levando em consideração mudanças no contexto político, econômico e cultural, mas também considera-se sobretudo as experiências e as trajetórias de vida dos atores, tendo em vista que a partir da análise relacional e processual desses fatores, pode-se explicar a emergência das manifestações em defesa da causa do transporte público e gratuito na última década na cidade de Aracaju. Tal investigação contou com um levantamento de notíciais sobre eventos de protestos vinculados à causa do transporte público na cidade de Aracaju a partir dos anos 2000 até os anos de 2013, em jornais de circulação local e em jornais eletrônicos, com o intuito de identificar quais eram as reivindicações mais defendidas e quais eram os movimentos sociais e atores políticos que se articulavam em defesa dessa causa. 
Em segundo lugar, foram realizadas observações participantes em eventos, reuniões, manifestações de rua, intervenções públicas, organizadas pelo Movimento Não Pago entre o período de 2011 a 2013 em Aracaju. A partir desse instrumento metodológico pôde-se verificar quais eram os espaços em que o movimento mais se representava, quais eram os repertórios organizacionais utilizados durante as manifestações, bem como em suas reuniões e em outros espaços de atuação, como a internet. Além disso, foi possível ainda observar seus apoiadores políticos e as reações das pessoas diante dos atos públicos feitos pelo Movimento. Foram realizadas ainda, entrevistas semiestruturadas e biográficas, que focalizaram na trajetória militante, escolar e profissional, bem como nas redes interpessoais das lideranças do Movimento Não Pago que atuaram como "pessoas-pontes" (Mische 1997; 2008) mediando, por exemplo, a articulação do movimento com outros movimentos sociais, a mídia e políticos partidários.

As próximas duas seções apresentam os argumentos colocados anteriormente para compreender a emergência e as formas de representação do Movimento Não Pago na cidade de Aracaju durante os anos de 2011 e 2013. Essas seções são seguidas da apresentação mais detalhada da importância do MPL, da Frente e das manifestações do Acorda Aracaju em junho de 2013, tanto para o surgimento quanto para a legitimação do Movimento na região estudada. $\mathrm{O}$ artigo, a partir desse detalhamento, foca na emergência do Não Pago, nas redes de articulação e nas experiências prévias de suas lideranças. Elucidando questões fundamentais para compreender a ação do Movimento durante os protestos de junho de 2013, que em Aracaju ficaram conhecidos como Acorda Aracaju. O artigo é concluído a partir de uma leitura específica sobre atuação do Movimento Não Pago entre o período de 2011 e 2013 que foca a sua análise, sobretudo, na atuação de mobilização de recursos e na utilização de determinados repertórios organizacionais utilizados pelos atores para a emergência e representação desse movimento.

\section{Movimentos em defesa da causa do transporte público em Aracaju/SE: MPL e Frente em Defesa da Mobilidade e do Transporte Público}

A partir de dados coletados em jornais impressos de circulação local na cidade de Aracaju (Jornal da Cidade, Jornal do Dia, Cinform) e por meio também de jornais eletrônicos, blog, Facebook, etc., notou-se que antes dos anos 2000 havia mobilizações e manifestações de rua em defesa da causa do transporte público na cidade de Aracaju. Contudo, essas eram periódicas e centralizadas na ação, principalmente, de representantes do movimento estudantil universitário da UFS, de trabalhadores e de políticos partidários que organizavam comissões para reivindicar meia passagem para os estudantes, passe-livre para os desempregados e aumento da frota, por exemplo (Siqueira 1983). A partir dos anos 2000, é possível observar uma mudança nesse quadro de manifestações ligadas à questão do transporte público em Aracaju, onde esses mesmos atores políticos (movimento estudantil universitário, trabalhadores e partidos políticos), mais uma juventude representada por coletivos de gênero e de cultura, bem como jovens que se definiam como militantes independentes, passam a se manifestar e se organizar de 
forma mais contínua em torno da reivindicação do transporte público e gratuito, sobretudo, da redução da tarifa, a tarifa-zero para estudantes e mobilidade urbana, como é demonstrado nos trabalhos de Santos (2014), Oliveira, Santos (2015).

Portanto, o argumento defendido nessa primeira seção é de que a emergência e a representação do Movimento Não Pago na cidade de Aracaju no ano de 2011 estão relacionadas aos interesses particulares das suas lideranças e de seus atributos pessoais, tal como a partir da articulação dessas lideranças com outros atores políticos que sustentaram a sua ação por meio de recursos externos (Mische 1997; Oliveira 2010; Oliveira; Santos 2015; Santos 2014; Tarrow 2009; Tilly 2010). Para compreender tal argumento, é preciso analisar dois movimentos que atuaram antes dos anos 2011 na cidade de Aracaju que contribuíram para a formação de uma rede de articulação, para a formação política de jovens e para a construção de um cenário em que recursos materiais, financeiros, humanos, bem como repertórios organizacionais poderiam ser mobilizados posteriormente por novos atores políticos para que reivindicassem a causa do transporte público e gratuito.

O primeiro é o MPL, tal movimento emergiu a partir de várias manifestações contra o aumento das passagens do transporte público no ano de 2003 em Salvador (Santos 2014; Maricato et.at. 2013; Gohn 2013). Essas manifestações que ficaram conhecidas como "Revolta do Buzú", deram início a um debate sobre a situação do transporte público nas cidades brasileiras, configurando o surgimento de movimentos sociais formados, sobretudo por jovens estudantes. Outras manifestações que também foram importantes para o fortalecimento e difusão da reivindicação do transporte público e gratuito, as manifestações em Florianópolis/SC que ficaram conhecidas como Revolta da Catraca Livre, em 2004. Já em 2005 o MPL-Brasil surge oficialmente no V Fórum Mundial Social (Maricato et.at. 2013). Segundo Borelli e Oliveira,

Nos anos 2000 os encontros do Fórum Social Mundial mobilizaram milhares de jovens preocupados com as questôes sociais mundiais; a marca destes encontros tem sido a heterogeneidade dos participantes: grupos socialistas e coletivos anarquistas, movimento gay e feminista, ecologistas de vários tipos, o movimento estudantil independente e grupos defensores de direitos humanos variados (Borelli; Oliveira 2010: 61).

Os anos 2000, como enfatizado na citação acima, há uma maior diversificação nos quadros de participação política dos jovens brasileiros, que não pode ser observado nas décadas anteriores, como destaca os trabalhos de (Abramo; Branco 2005; Borelli; Oliveira 2010). Os jovens passam a ter uma múltipla militância e reivindicar diferentes causas (Mesquita 2003; 2008; Mische 1996; 1997; 2008). Nesse sentido, a participação do MPL na cidade de Aracaju entre o período de 2003 a 2010, foi fundamental nos seguintes pontos: (1) difundir repertórios de organização em defesa, sobretudo da tarifa zero, algo que em outros estados já estava sendo feito; (2) a formação política de jovens estudantes universitários e também secundaristas, por meio de debates e cine debates, tendo como discussão principal a tarifa zero, o transporte público gratuito, a realidade do transporte público brasileiro e a mobilidade urbana; (3) estabelecer uma rede de articulação política entre movimentos sociais que defendiam diferentes demandas (trabalhistas, culturais, de gênero, educacionais, etc.), mas que viam na defesa da tarifa zero um denominador comum, uma identidade comum entre esses diferentes grupos; (4) por fim, pro- 
mover a circulação de repertórios simbólicos, como também o uso de novos espaços de atuação, como o da internet, por meio de blog, para se manifestarem e organizarem mobilizações na cidade.

Segundo Clemens, "os modelos de organização compreendem tanto padrões para os arranjos de relações no interior de uma organização, como conjuntos de roteiros para a ação culturalmente associados com esse tipo de organização" (Clemens 2010:164). A partir disso, notou-se com os relatos de ex-militantes do MPL em Aracaju, que o padrão de organização do movimento priorizava ações de conscientização sobre a tarifa zero e, de forma mais ampla, sobre o transporte público e a mobilidade urbana em Aracaju e no Brasil. As intervenções públicas se caracterizavam, principalmente, pelo caráter artístico e simbólico, se utilizando do lúdico e da dramaturgia durante os atos públicos e passeatas, com o intuito de chamar a atenção da população e do Estado para a causa defendida. Segundo Flávio Marcel, ex-militante do Movimento Passe Livre, atualmente uma das lideranças do Movimento Não Pago, o movimento começou a atuar em 2003 no estado de Sergipe e acabou entre 2007 e 2008. Contudo, a partir da coleta de dados no blog do MPL em Aracaju verificou-se que sua última atualização foi em 2010, isso nos indica que entre 2008 e 2010 o movimento começou a perder espaço e as intervenções públicas foram se tornando escassas, porém aponta que nesse mesmo período havia militantes que ainda mantinham o blog atualizado e que mesmo em menor proporção havia uma organização e uma mobilização feita por alguns militantes.

Com base na entrevista com Flávio Marcel e Demétrio Varjão, o MPL não conseguiu, durante seu período de atuação em Aracaju, a redução da tarifa do transporte público bem como impedir o aumento. Mas isso não implicou na efetividade e na importância que esse movimento teve, por exemplo, na formação política de jovens em torno da causa em Aracaju. Segundo Marcel, a atuação do Movimento foi de suma importância para iniciar um debate mais profundo a respeito das condiçóes do transporte público na cidade, sobretudo no que corresponde ao direito ao passe livre e a mobilidade urbana (Santos 2014). Marcel chama atenção de que apesar do movimento atualmente não se articular no estado de forma organizada, ou seja, como um movimento social, ainda tem muitos militantes que se identificam com o modelo de atuação do movimento e atuam de forma independente na cidade de Aracaju (idem.).

Outra questão destacada pelos dois ex-militantes do MPL-Aracaju e percebidas durante a pesquisa, é que o modelo de organização e atuação do movimento não conseguia "prender" os militantes, pois não os agradava. Isso se torna interessante na medida em que entendemos como Clemens (2010) destaca que os modelos organizacionais são intermediários, ou seja, os mesmos podem variar com as mudanças tanto institucionais, mas também a partir dos atores que constroem o conjunto de ações e roteiros de mobilização. Nesse sentido, pode-se destacar também que nas últimas décadas as formas de participação política dos jovens se transformaram. Os espaços que eles atuam, bem como suas lógicas de mobilização têm se diferenciado de décadas anteriores (Mesquita 2003; 2008; Mische 1997; Gohn 2013), o que possibilita compreender que alguns militantes do MPL-Aracaju não reconheceram mais o padrão de organização escolhido por esse movimento e buscaram ou criaram novos movimentos e coletivos, bem como outros espaços de mobilização para militarem. 
O segundo movimento que precisou ser analisado para entendermos como foi possível a formação de uma rede de articulação política em torno da reivindicação do transporte público e gratuito, da formação política de jovens e da construção de um cenário favorável para o surgimento de novos movimentos sociais em favor dessa causa na região, é a Frente em Defesa da Mobilidade e do Transporte Público em Aracaju, que tinha como slogan "Não Pago". Tal Frente surgiu no início de 2010, a partir de um conjunto de entidades que aliava sindicatos, frentes sindicais, partidos políticos, movimentos sociais e militantes que atuavam de forma independente, ou seja, que não estavam vinculados a nenhuma organização, partido político e movimentos sociais (Santos 2014; Oliveira; Santos 2015). Esta Frente era composta por cerca de vinte entidades, que reivindicavam principalmente a redução da passagem do transporte público que estava previsto para aumentar de 2,10 para 2,25 (blog, notícias na Infonet, Facebook).

O principal objetivo da Frente era a redução da tarifa do transporte público e tal objetivo levava o movimento a ter uma dinâmica de atuação e organização diferente da do MPL, uma vez que seus interesses eram específicos, bem como os atores que participavam estavam como representantes de determinado movimento, partido político, sindicato, etc., o que proporcionava em alguns momentos, conflitos internos e a falta de compromisso de algumas entidades em atos e eventos organizados por elas, como pôde ser verificado a partir das observações com os participantes, em conversas e entrevistas com militantes independentes e do Movimento Não Pago. Seu modelo de organização, portanto, se constituía por um conjunto de repertórios que incluía atos públicos, passeatas, panfletagens e reuniões. A Frente se organizava normalmente no início do ano, quando era anunciado o aumento da tarifa do transporte público, o que caracteriza seu modelo de atuação, bem como revela estratégias de atuação diferentes, por exemplo, do MPL para impedir o aumento e/ou para exigir a redução da tarifa.

Contudo, esse modelo tinha algumas fragilidades. Entre elas, a atuação esporádica e a falta de continuidade das ações após o aumento da tarifa (Santos 2014; Oliveira; Santos 2015). Outra que pode ser destacada também são as divergências internas em torno da causa reivindicada. Durante as entrevistas e conversas, notou-se que não havia um consenso entre as entidades sobre a causa reivindicada, ou seja, nem todos concordavam com a tarifa zero, reivindicação que aparecia nos folhetos e panfletos distribuídos pelos militantes durante manifestações, nos ônibus, nos terminais rodoviários e em panfletagens no centro de Aracaju. Essas divergências, assim como a heterogeneidade dessa Frente, descentralizava a questão da redução da tarifa (mesmo que a redução fosse o objetivo principal) e permitia que outras reivindicações se agregassem, por exemplo, a da moradia. Com relação a isso, chama-se atenção para dois pontos: primeiro, agregar outras demandas fazia com que as manifestações de rua e os atos públicos se massificassem. Algo que era positivo para a representação e o poder de pressão do movimento sobre os seus opositores; segundo ponto, essa diversidade de causa e de interesses particulares dos atores e de suas respectivas entidades dificultava a organização e coesão da Frente.

Segundo Tarrow, determinados atores políticos tendem a desaparecer a partir de mudanças no contexto político e de ciclos de protestos que podem promover oportunidades políticas para novos atores se manifestarem (Tarrow 2009). Já Cefaï, enfatiza que é importante compreender as redes sociais de um movimento para analisar como o ele surgiu e destaca três pontos: o primeiro ponto refe- 
re-se às organizações e redes que preexistem à ação coletiva e são componentes do agenciamento que as caracterizam; no segundo ponto, destaca que é preciso explorar os regimes de ação por meio da navegação por tramas reticulares ou montagens organizacionais; por fim, o terceiro ponto diz respeito à representação do coletivo, pluralidade de gramáticas do eu, do tu e dos nós (Cefaï 2009). Para a discussão presente, vamos destacar apenas o primeiro ponto, pois este nos ajuda a analisar a emergência e as formas de representação do Movimento Não Pago na próxima seção. De acordo com isso, pode-se elucidar alguns pontos em que a atuação da Frente contribuiu para a defesa do argumento colocado no início dessa seção: (1) o caráter heterogêneo da Frente permitiu aos militantes independentes estabelecer redes e laços, tanto com as entidades quanto com outros militantes independentes; (2) os recursos financeiros, humanos, materiais, simbólicos e políticos mobilizados pela Frente durante sua atuação, foram incorporados pelo Movimento Não Pago; (3) os militantes que diziam atuar como militantes independentes na Frente, tinham uma militância tanto prévia quanto atual, no movimento estudantil universitário da UFS; (4) e por fim, com a desarticulação da Frente, quando esta não consegue a redução da tarifa no início de 2011, surge um cenário favorável para os militantes se organizarem em torno da causa do transporte público, da redução da tarifa e da mobilidade urbana em Aracaju, uma vez em que o debate e uma rede de militantes queriam continuar lutando em defesa daquelas causas (Santos 2014; Oliveira; Santos 2015).

Verificou-se a partir da análise dos dois movimentos que estes tinham modelos de organização diferentes, mas que alguns repertórios de ação se repetiam, como os atos públicos e as reuniões. Além disso, outro ponto comum aos dois é que lideranças do Movimento Não Pago atualmente participaram de forma ativa tanto no MPL quanto na Frente, o que permitiu a eles estabelecer redes e mobilizar recursos externos para sustentar suas ações. Um exemplo disso é o financiamento de xerox dos panfletos distribuídos pelo Movimento durante suas manifestações e espaços cedidos por sindicatos ou centrais sindicais para o movimento realizar eventos como reuniões ou seminários ${ }^{3}$ de formação política (Santos 2014). Outro ponto crucial está relacionado aos militantes ditos independentes, ou seja, aqueles que atuavam na Frente, mas que não estavam vinculados a nenhuma entidade que a formava. Essa questão é interessante porque durante as entrevistas, as observações participantes, bem como de leituras feitas na página do movimento no Facebook e de jornais eletrônicos (Infonet), notou-se que esses militantes atuavam em centros acadêmicos dos seus respectivos cursos, que não eram filiados a partidos políticos, todavia militavam neles, e que alguns desses militantes tinham experiências de militância diversificadas como ainda algumas possuíam um capital escolar e profissional que foram mobilizados no processo de surgimento, representação e consolidação do Movimento Não Pago em Aracaju, como veremos de forma mais detalhada na próxima seção.

3 Os Seminários de Formação Política e Organização do Movimento Não Pago: o primeiro ocorreu em setembro de 2011; o segundo no primeiro semestre de 2012; o terceiro foi em, 10/11/2012; e por fim o quarto em, 27/07/2013. 


\section{Repertórios organizacionais, redes sociais e experiências pessoais: emergência do movimento não pago}

Como demonstrado anteriormente, o MPL e a Frente contribuíram para as reivindicações no âmbito do transporte público e da mobilidade urbana em Aracaju, uma vez que permitiu criar condições prévias para novos atores se manifestarem em defesa dessa reivindicação. A participação de alguns militantes que posteriormente fundariam o Movimento Não Pago, nos dois movimentos, possibilitou-lhes acumular conhecimento e experiências, bem como ampliar suas redes em diferentes espaços de militância da região. Contudo, é sabido que alguns desses militantes já estavam vinculados a outros espaços de militância que não foram necessariamente frutos de sua participação naqueles dois movimentos, como por exemplo, a militância desses no movimento estudantil universitário e secundarista, em torcidas organizadas, em sindicatos e partidos políticos (Santos 2014; Oliveira; Santos 2015). A emergência do Movimento Não Pago, portanto, implica compreender tanto como se deu a inserção de suas lideranças nesses espaços de militância preexistentes, quanto os acionamentos de determinadas identidades daqueles que foram os fundadores do movimento e que permitiram ao movimento mobilizar redes e modelos de organização diferenciados.

Sendo assim, o argumento defendido nessa seção é que as redes sociais, os repertórios organizacionais preexistentes e as experiências pessoais das lideranças do movimento implicaram em modelos de organização diferenciados que permitiram a emergência, consolidação e continuidade do Movimento. Para a defesa de tal argumento, é preciso entender a partir da abordagem de Mische (1997) sobre identidade, como as experiências pessoais e as relações interpessoais dos atores implicam na construção da identidade do movimento, bem como nos seus modelos de organização. Segundo a autora, pode-se pensar a partir de três conceitos de identidade: identidade como reconhecimento; identidade como experimentação; e por fim, identidade como orientação. Estes três conceitos permitem conhecer como a formação da identidade do movimento, bem como dos seus militantes, não se constrói de forma imediata, mas de forma processual, a partir das interações sociais.

A identidade como reconhecimento, segundo Mische "são as qualidades agregadas de categorias sociais, como classe, gênero, raça ou nacionalidade" (idem:141). Já no caso da identidade como experimentação, a autora acredita que "para entender a dinâmica temporal de identidades como influência na ação coletiva, é preciso analisar como elas interagem com o ciclo de vida da pessoa” (idem.). Por fim, o ultimo conceito: a identidade como orientação. Para Ann Mische:

Dá-se pouca atenção ao papel de identidades como mecanismos de orientação, usados pelos atores para dar direção e formar à ação futura. Identidades não são apenas categorias sociais que em si dão estruturas e sentidos às redes sociais, mas são mobilizadas de forma seletiva, segundo os projetos emergentes dos atores pelos quais eles tentam resolver conflitos e criar novas oportunidades de ação (Mische 1997:140).

De acordo com isso, notou-se com as entrevistas semiestruturadas com as lideranças do Movimento Não Pago, que a maioria dos militantes tinha entre 17 e 30 anos de idade; que entre as lideranças 
alguns já possuíam o ensino superior completo e faziam pós-graduação lato sensu, que as reivindicações da classe trabalhadora eram demasiadamente importantes na vida dessas lideranças e serviam como reivindicação que orientava as reivindicações no âmbito do transporte público. Isso ficou ilustrado quando Flávio Marcel, citado anteriormente, liderança do Não Pago, estudante de educação física e no momento da pesquisa encontrava-se desempregado, vivendo de seguro desemprego, lembra-se de fatos ocorridos em sua vida ainda na infância, quando sua mãe precisava ir trabalhar e pegar o transporte público, ou quando ele precisava ir para escola e as condiçóes do transporte público eram precárias, além do valor da tarifa que era contraditório ao serviço prestado. A liderança ressalta durante a entrevista que o ser humano está sempre em construção e reconstrução, a partir das situações e do meio em que ele vive. Com relação a isso e aos motivos que o fizeram participar da militância, tanto em defesa da reivindicação no âmbito do transporte e da mobilidade quanto às reivindicações especificamente trabalhistas, destaca-se a seguinte narrativa:

A gente vai passando por diversas situações. A gente não pode determinar uma única coisa porque o indivíduo é construído socialmente pela sua construção familiar. Desde criança até morrer, você vai sempre se reconstruindo independente. Diversas coisas aconteceram, morava no Eduardo Gomes. Sim, tinha dificuldades... Não financeiras, mas visualizava algumas dificuldades de alguns colegas, algumas dificuldades de quando você chega em sua casa, desde criança mesmo, você chega em sua casa, vê que você não tem uma coisa e seus colegas têm outras, você tem que realizar uma atividade para um colega que você vê que depende de você. Estas coisas já vão lhe estruturando na vida, pegando transporte público desde pequeno, eu sempre tive essa vontade de gostar de assistir documentários. Isso justamente facilita bastante porque você vai vendo outro mundo que você não visualiza nesses meios de comunicação que a gente tem hoje. E o dia a dia, eu morava na periferia do Bugio, já participei de torcida organizada, já fui da Trovão Azul e também acho que contribuiu bastante pra isso porque a gente visualizava que os camaradas que podiam oferecer e o que eles ofereciam naquele momento eu percebi, aquela revolta que eles tinham que poderiam ser direcionada para outras coisas, como eu fiz. Eu estava na Trovão Azul, poderia pender para um lado errado, pendi pro lado que, de certa forma, tenho muita coisa pra contribuir para os trabalhadores. Acho que essa é uma das coisas que contribuíram mais para eu entrar na vida da militância (Caderno de campo, Flávio Marcel, 29 de agosto de 2013).

A partir da narrativa de Flávio Marcel, percebe-se a importância de observar como as interações em outros espaços de militância contribuem para compreender a sua atuação no Movimento Não Pago. Sua participação em torcida organizada lhe possibilitou construir uma identidade que pudesse ser acionada em momentos de conflitos mais tensos e agressivos com os opositores do Movimento Não Pago. Como o próprio ressaltou aqueles que têm mais experiência de militância durante manifestações, como, por exemplo, nos Acordas Aracaju, ficam em pontos mais tensos e arriscados, sendo ele um desses militantes que atua durante as manifestações nesses pontos. Marcel se destacava no Movimento, justamente por ser um dos militantes mais experientes em termos de manifestações de rua. Tinha forte articulação com sindicatos e movimentos sociais ligados a demandas trabalhistas, sendo que ele já tinha sido funcionário de um sindicato em Aracaju. 
Outra liderança que se destacava era Demétrio Varjão, agora não mais pela sua trajetória de militância, mas pelos recursos profissionais e escolares que detinha. Formado em economia pela UFS, mestrando em Comunicação pela referida instituição e estudante do curso de Direito na maior faculdade particular da cidade, relata que antes de participar como militante independente na Frente, havia tido uma militância no centro acadêmico de economia da UFS, onde conheceu o MPL, mas não chegou a participar deste. Suas experiências de militância não deram o mesmo respaldo que suas experiências profissionais e escolares, uma vez que os recursos mais acionados durante suas ações estavam ligados a estas duas esferas de vida. Isso torna-se compreensível quando a Frente é desarticulada ainda no primeiro semestre de 2011 e Demétrio Varjão, Alexis Pedrão e Luiz Andrade resolvem fazer reuniões para estudar o transporte público e a mobilidade urbana na cidade de Aracaju, esses três militantes se tornam inicialmente as principais lideranças do Movimento Não Pago. De acordo com isso, Varjão, com a ajuda de um professor de economia da UFS, elabora um laudo técnico sobre o transporte público da cidade, denunciando fraudes, irregularidades e precariedades nas condições de trabalho dos rodoviários. Como demonstrada na descrição de Demétrio Varjão:

$\hat{E}$, a Frente fez algumas intervenções. $\hat{E}$, além destas organizações tinha muita gente independente também. Inclusive eu era independente de tudo, não participava destas organizações ainda. $\mathrm{Na}$ verdade eu vinha do centro acadêmico, não era nada muito orgânico assim, então em 2011 teve aquele processo... A passagem foi aumentada para 2,25 e todo ano sempre foi assim. As pessoas se mobilizavam para fazer uma mobilização, contra o aumento, mas após o aumento ser concedido, as coisas morriam. Para a discussão sobre o transporte, era sempre muito pontual no começo do ano. Quando, quando, discutia-se a proposta de aumento. É, quando as coisas foram esfriando, algumas pessoas resolveram continuar estudando o transporte público de Aracaju. No caso, foram três pessoas especificamente: foi eu, Luizinho e Alex Pedrão. Aí a gente decidiu continuar com o estudo do transporte e da legislação... A gente decidiu tornar o movimento Não Pago, um movimento de fato, uma organização própria, ou seja, com suas próprias características, seus próprios princípios, etc., sua própria forma de organização. Então a gente realizou em 2011, um seminário de formação do Movimento Não Pago. Meados de 2011, que foi a partir dali que o movimento criou vida assim. O Não Pago deixou de ser uma Frente para ser um movimento (Caderno de Campo, Demétrio Varjão, 15 de setembro de 2013).

Inicialmente, como apresentado no trabalho de Santos (2014) esses três militantes buscavam tornar o "Não Pago", que antes era a Frente, um movimento autônomo e independente, que pudesse delimitar suas reivindicações, seus princípios, que tivesse uma continuidade no debate a respeito do transporte público e da mobilidade na cidade de Aracaju. Nesse processo, os representantes do Movimento buscaram se diferenciar tanto do MPL quanto da Frente em termos de repertórios de organização, dos espaços de atuação, articulação política, etc. Foi lançado, assim, um vídeo ${ }^{4}$ no canal do Youtube, no dia 25 de dezembro de 2011, com o titulo "O transporte Público Coletivo em Aracaju - Movimento Não Pago!". Este vídeo tinha como objetivo apresentar, segundo os militantes, a realidade do transporte público de Aracaju, como também apresentar o Não Pago como um movimento social. As estratégias de

$4 \mathrm{O}$ vídeo com duração de cerca de 10 minutos pode ser consultado em: https://www.youtube.com/watch?v=3pt5wfwhaQI Acesso em: 11. Dez. 2016. 
divulgação e de mobilização do movimento partiram tanto das mídias sociais online, como Facebook, Youtube, Blog, Tumblr e Orkut, como também de formas mais tradicionais como panfletagens e sessões de debates. Como pode ser observado na narrativa abaixo, os militantes reconheciam a importância do MPL e da Frente, contudo, enfatizavam como estes não conseguiram a redução da tarifa do transporte público quando atuaram:

Quando eu seguia o MPL, a gente tentou realizar atos. 2009, 2010, 2011... Atos contra o aumento da passagem. E em si não tinha um efeito considerado, né?! Não incomodava de fato o poder público para chamar atenção. Já a gente não conseguia denunciar alguma irregularidade que a gente já visualizava; não conseguia de alguma forma dar uma vida e não conseguia trazer a população pra próximo dessa luta do transporte público de qualidade. Aí foram uns dos fatores que nós visualizamos que não conseguimos em 2011 e que é necessário ter uma organicidade, que o movimento tinha que acumular sobre isso, estudar sobre isso, saber que porque nós conseguimos ver nos últimos anos a distinção do MPL, as coisas não tão mudando, não tinham como andar porque tinham limitações. Estas articulações dos outros movimentos, cada movimento tinha a sua leitura sobre o transporte e estas leituras não vinham dando, não vinham acrescentando na luta, é pela gratuidade, pela redução da passagem, aí foi também algo que norteou e a gente avaliou que era necessário ter um movimento específico, popular, mais do que isso, para agregar todos os setores do transporte" (Caderno de campo, Flávio Marcel, 29 de agosto de 2013).

O MPL era um movimento de fato, que existia aqui em Aracaju e em várias cidades do Brasil. Algumas pessoas que fizeram parte logo no início do Não Pago eram do MPL, mas tinha diferença. O MPL era uma organização em si, era uma organização própria. O Não Pago, ele não tinha este caráter, ele não era uma organização própria, ele era uma frente, eram várias organizações que formavam a Frente que se chamava Não Pago. Mas tinha uma relação direta. Pessoas que vieram do MPL e também por que o movimento é referência pra qualquer movimento social que luta pelo transporte, era o Movimento Passe Livre. Desde, não sei, mas desde o início da década de 2000, o MPL já vinha atuando em outras cidades e aqui também. Então tem esta relação. A pauta é a mesma. Na verdade, a forma de intervenção, de atuação, é a mesma, é muito parecida, muito mesmo. Mas o MPL aqui acabou. Acabou aqui. Não tenho certeza, mas o MPL, ele não, a forma de organização deles não era assim muito proporcional... Assim, há uma, há organicidade dos militantes, eu acho! Não sei bem, mas ele não vingou aqui, mas tem esta relação direta, que alguns militantes vieram do MPL (Caderno de Campo, Demétrio Varjão, 15 de setembro de 2013).

O Movimento Não Pago surge, portanto, no segundo semestre de 2011 com o lançamento do vídeo no Youtube, mencionado anteriormente. Como apresentado na narrativa de Varjão, a pauta e a forma de atuação e de intervenção do Movimento Não Pago são as mesmas do MPL, porém esse último movimento não conseguiu "vingar" na cidade porque na visão do militante, como eles se organizavam não era "proporcional a uma organicidade dos militantes". A esse respeito, alguns autores têm demonstrado como o caráter múltiplo e diversificado das formas de atuação, principalmente no surgimento de movimentos que buscam formas não institucionalizadas de ação, tem surgido nos últimos anos e configurado novas formas de participação política dos jovens (Mesquita 2003; 2008; Mische 1996; 1997; 2008). Em consenso com isso, os atores que lutaram para a formação e surgimento do Movimento Não Pago, utilizaram repertórios de ação utilizados anteriormente tanto pelo MPL quan- 
to pela Frente, como passeatas, intervenções artísticas e dramáticas, atos públicos, assembleias gerais, reuniões, abaixo-assinados e cine debates. No entanto, diferentemente dos dois movimentos anteriores, esse conseguiu acessar outros espaços e disponibilizava de mais recursos. Os mesmos conseguiram acessar algumas periferias de Aracaju, por meio da mediação de "pessoas-pontes" vinculados a outros movimentos que atuavam nessas regiões, conseguiram falar durante assembleia pública na Câmara dos Vereadores e apresentar o laudo técnico feito por eles. Além disso, outro espaço demasiadamente explorado foi o espaço online, a partir das redes virtuais, que no MPL e na Frente já eram utilizados, porém de forma pouco representativa.

Outro aspecto que distinguia a forma de mobilização do Não Pago dos outros movimentos citados era a heterogeneidade de suas redes que incluía movimentos que pautavam questões de gênero, liberdade sexual, cultural, educacional, e, sobretudo, trabalhistas. Como já mencionado em outro momento do artigo, Tilly (2010) ressalta que é preciso analisar um movimento social interligando-o com outros âmbitos da sociedade e que as redes de apoiadores não constituem o movimento em si, mas não se pode desconsiderá-las da análise. Sendo assim, se fez necessário analisar o potencial dessas redes na emergência e representação do Movimento Não Pago em Aracaju, pois elas possibilitaram ao movimento a mobilização de recursos simbólicos, como também de organização.

De acordo com isso, uma rede de articulação importante foi a dos motoristas e cobradores do transporte público, eles têm um histórico de luta na cidade de Aracaju, com grandes paralisações e greves, sempre lutando por melhores condições de trabalho e reajuste salarial. O Movimento Não Pago, nos anos de 2012 e 2013, apoiou as paralisações feitas pelos rodoviários, enxergando que eles sofrem com o descaso das empresas que gerenciam o transporte público de Aracaju e Grande Aracaju, que o sindicato dos rodoviários tem pouca força representativa e que há conflitos entre a categoria e o próprio sindicato que os representam (Santos 2014; Oliveira; Santos 2015). O Movimento Não Pago apoiava, portanto, as reivindicações da categoria dos rodoviários da cidade de Aracaju e Grande Aracaju. Isso nos permite ressaltar que esses laços com essa categoria possibilitaram ao movimento inserir-se em outro espaço de atuação, como ganhar o apoio não apenas dos trabalhadores, mas também de seus familiares e amigos, como ressaltado na entrevista.

A diminuição da tarifa do transporte público de Aracaju é a reivindicação central do Movimento, no entanto, gira em torno desta pauta uma série de questões que envolvem a causa da mobilidade urbana e todas as reivindicações ligadas ao âmbito do transporte público, por exemplo, o aumento das linhas que interligam as diferentes regiões da cidade ao campus universitário, que fica na cidade de São Cristóvão. Essa reivindicação é feita desde o ano de 1983, como se viu no início do artigo e que pode ser observado nesses textos retirados do blog do movimento: [...] a tarifa é apenas a ponta do iceberg - ainda que, mesmo assim, a disputa sobre seu preço seja causa suficiente para revoltas populares e trabalhistas de proporções invulgares. Nesse sentido, é importante enxergar a paralisação dos rodoviários como um dos fatores de avaliação de todo o sistema. Os trabalhadores rodoviários sofrem os desmandos da classe patronal, principalmente, por falta de um sindicato forte e atuante além da ausência do Poder Público, por meio de Conselho Municipal, que fiscalize os donos das empresas (Movimento Não Pago 2013)5.

5 Ver mais em: http://movnaopago.blogspot.com.brAcesso em: 20. Dez. 2016. 
Chamamos também a responsabilidade do ministério público do trabalho e da OAB para que atuem junto aos rodoviários nesse caso. Estamos focados na luta contra o aumento da passagem, mas não deixaremos de lado as outras pautas que temos apresentado à sociedade: a defesa dos trabalhadores rodoviários é uma delas. A nossa luta contra o aumento e em defesa dos empregos é uma só, é a luta de classes. E sabemos que estamos usuários e rodoviários do mesmo lado, o lado dos trabalhadores e dos explorados (Movimento Não Pago 2013) ${ }^{6}$.

A redução da tarifa era a causa comum a todos os movimentos que apoiavam o Não Pago, pois como se observou nos atos públicos, os estudantes, jovens, principalmente da periferia, os desempregados e os trabalhadores exigiam a redução, pois precisavam diariamente do meio de transporte para trabalhar, estudar, procurar emprego ou mesmo para o lazer, o que demonstra que essa reivindicação era básica e extremamente necessária para essas categorias. Partidos políticos, principalmente através de políticos partidários específicos, também se articulavam com o movimento em torno dessa reivindicação. Segundo militantes e lideranças do Movimento Não Pago, o movimento não tem vínculo formal com nenhum partido político, porém o movimento se articula com os partidos de esquerda. Segundo as lideranças entrevistadas, o movimento em si não levanta bandeiras de partidos, mas estão articulados com o PSOL, PSTU e o PCB. Além disso, alguns militantes do movimento militam em partidos políticos, um exemplo disso, é um dos seus fundadores, Alexis Pedrão, que se candidatou a vereador de Aracaju nas eleições de 2012, pelo PSOL.

Foi interessante observar como as reivindicações no âmbito do transporte público e da mobilidade urbana influenciaram as campanhas das eleições de 2012. Nesse sentido, os candidatos a prefeito ${ }^{7}$ de Aracaju nas eleições de 2012, tinham nas suas principais propostas a questão da mobilidade urbana. Para o atual prefeito de Aracaju, João Alves Filho, é preciso ter uma visão global sobre a questão da Mobilidade Urbana, é preciso ter uma visão do presente e do futuro. Em entrevista concedida ao G1 em 25/08/2012, disse o seguinte sobre a questão do transporte público: “[...] o trânsito, transporte coletivo, está uma decadência terrível. As pessoas viajam como sardinhas em lata. É uma coisa deprimente”. No ano de 2012 houve o congelamento da passagem do transporte público. Diversas manifestações e denúncias foram feitas sobre o descaso do transporte público. Não somente o atual Prefeito João Alves Filho como os outros candidatos, aproveitaram o discurso dos manifestantes para lançar suas propostas, com ideias que propunham resolver os problemas da mobilidade urbana e do transporte público da cidade de Aracaju.

Além disso, é preciso ressaltar que o Movimento Não Pago tem articulações com partidos políticos, vereadores, que os apoiam e que compartilham da sua causa na Câmara de Vereadores. Em uma observação participante no ano de 2013, um militante falou o seguinte: "É preciso ter um de nós lá, lá na Câmara, só assim a gente vai conseguir atenção, vai conseguir alguma coisa”. O movimento fez um banner denunciando os vereadores que aprovavam o aumento da passagem do transporte público

6 Ver mais em: http://movnaopago.blogspot.com.brAcesso em: 20. Dez. 2016.

7 Os candidatos e seus respectivos partidos políticos foram, Almeida Lima (PPS), João Alves Filho (DEM), Reynaldo Nunes (PV) e Vera Lúcia (PSTU). 
e divulgando aqueles vereadores que não aprovavam o aumento, lançaram este banner nas redes sociais e o expôs em algumas manifestações na Câmara de Vereadores.

É interessante perceber também que muitos militantes do Movimento Não Pago militam em partidos políticos e ocupam ou já ocuparam cargos em sindicatos, como também é importante perceber as profissões de alguns dos militantes: advogado, economista, geógrafo, designer, etc. São profissões que, juntamente com uma rede de relações, possibilita a ocupação de cargos dirigentes (Oliveira 2010). A vinculação entre partidos políticos e o Movimento Não Pago é clara, segundo lideranças do movimento, é preciso haver partidos políticos, terem esta representatividade, mas é preciso que este realmente represente o povo que os elegem.

Em Sergipe, especificamente na capital, podemos perceber políticos que resgatam a história de militância no movimento estudantil da UFS, em seus discursos políticos. Um exemplo disso é o ex-governador Marcelo Déda (PT), que já esteve à frente do DCE, e o ex-prefeito de Aracaju Edvaldo Nogueira (PCdoB), como também o vereador Iran Barbosa (PT), que participava do movimento estudantil da Universidade e já ocupou cargos dirigentes no Sindicato dos Trabalhadores da Educação do Estado de Sergipe (SINTESE). Em consonância com isso, ressalta-se que um dos apoiadores do Movimento Não Pago na Câmara dos Vereadores é o vereador Iran Barbosa, que em uma das manifestações em frente à intituição, foi entrevistado e disse que era contra o aumento da tarifa do transporte público em 2013. Além desse Vereador, a candidata não eleita à prefeita de Aracaju nas eleições de 2012, Vera Lúcia (PSTU), também apoia o Movimento Não Pago mediando algumas ações entre o movimento e os vereadores durante as manifestações.

Analisando o período entre 2011 e 2013 classificam-se três momentos distintos durante a trajetória do Movimento: o primeiro corresponde à fase inicial do movimento, no segundo semestre de 2011, quando se torna "independente" da Frente. Segundo os militantes, o Movimento constrói suas próprias regras, seu próprio discurso, suas próprias formas de representação a partir desse momento. Quando o movimento era vinculado a Frente, o modelo organizacional e as formas de atuação eram delineados pelo conjunto de entidade que o compunha, sendo que, cada entidade tinha uma leitura particular sobre formas de intervenção pública e também sobre as reivindicações no âmbito do transporte público. Segundo os militantes, é a partir do momento que o movimento "ganha vida" que eles conseguem se organizar de forma mais unificada e sólida, uma vez que passam a traçar seus próprios princípios de atuação e se aprofundam no estudo da legislação sobre o transporte público da cidade de Aracaju e Grande Aracaju. Apesar dos atores ainda não disporem de muitos recursos e ainda não terem ganhando espaço na mídia televisionada foi um momento no qual os militantes estavam mobilizando suas redes e os recursos disponíveis, como o espaço virtual.

O segundo momento, considerado por Santos (2014) um dos momentos de apogeu do Movimento, é nos anos de 2012, quando o movimento consegue impedir o aumento da tarifa do transporte público. Esse acontecimento possibilitou que o movimento ganhasse espaço na mídia, reconhecimento da população, como também o número de militantes que fazia parte efetivamente do movimento crescesse. Com base nas entrevistas, uma das preocupações e desafios do Movimento Não Pago para o ano de 2012 era tanto dialogar com os vereadores para não ocorrer os aumentos, como também realizar 
manifestações de rua, conscientizar a população e também fortalecer sua organicidade por meio de estudos e debates sobre o transporte público e a mobilidade urbana. Então, o movimento se preocupou em ampliar suas redes de relações, definir suas pautas, regras e princípios, como também diversificar seus repertórios de ação diante das situações que iam sendo impostas ao movimento, como pode ser observado nos eventos de protesto organizados pelo movimento. Em alguns desses, era possível ver os manifestantes acorrentados nos portões do Sindicato das Empresas de Transporte de Passageiros de Aracaju (SETRANSP), queima de pneus nas entradas dos terminais rodoviários e mortes simbólicas de vereadores e do prefeito que era contra a redução da tarifa (Santos 2014). Segundo os entrevistados, essas formas de ação só eram utilizadas quando as reuniões e o diálogo com representantes do Estado não ocorria.

O terceiro e último momento diz respeito ao ano de 2013, de forma específica, ao mês de junho, quando acontece o Acorda Aracaju e o Movimento Não Pago se torna porta-voz dessas manifestações, que ao todo foram cinco atos (Santos 2014; Oliveira; Santos 2015). Os protestos de junho de 2013, em âmbito nacional, proporcionaram ao movimento mais visibilidade a partir do Acorda Aracaju, organizado pelo conjunto de movimentos sociais, tendo como protagonista o Movimento Não Pago. Além desses movimentos, nos três primeiros Acordas foi possível perceber uma maior participação da população e uma heterogeneidade de pautas e atores políticos, o que não pôde ser visto nos dois últimos, quando bandeiras de partidos políticos e centrais sindicais começaram a se ampliar durante as manifestações. De acordo com isso, durante essas manifestações pode-se considerar que o outro momento de apogeu na trajetória do Movimento foi esse, por alguns motivos. Primeiro, pelo seu protagonismo, legitimidade e reconhecimento para atuar como porta-voz durante essas manifestações; segundo, por ter ampliado suas redes e disponibilizado de mais recursos materiais e simbólicos, bem como o reconhecimento da mídia televisionada (mesmo que tenham sido reconhecidos de formas negativas em alguns momentos); terceiro, pelas transformações na forma de organização do movimento, pelo aumento de número de participantes que houve após esta onda de protestos, que chegou a cerca de trinta militantes atuando de forma efetiva do movimento.

Como ressaltado por Flávio Marcel "Antes do Gigante acordar, a luta já havia começado em 2003", quando ocorrem as manifestações em Salvador e no caso de Aracaju, quando o MPL começa a atuar. Segundo o militante, eles já esperavam que grandes manifestações em torno das reivindicações no âmbito do transporte público acontecessem, no entanto, não sabiam quando iam ocorrer, mas sabiam que essas manifestações era resultado de uma luta antiga. Durante os Acordas Aracaju, nos dois últimos especificamente, era possível ver como as redes do Movimento se articulavam. Partidos políticos, sindicatos e centrais sindicais apoiavam o Movimento, por exemplo, disponibilizando trio elétrico durante as manifestações (algo que a população não apoiou durante o primeiro Acorda). Em uma observação participante feita após os Acorda Aracaju, durante uma manifestação realizada pelo Movimento Não Pago, Calçadão da Rua João Pessoa e no centro de Aracaju, no dia 17 de julho de 2013, ficou claro esta ação recíproca entre estes atores políticos. Nessa manifestação, as bandeiras das centrais sindicais estavam mais presentes que as bandeiras do Movimento Não Pago, além disso, os representantes das centrais falavam mais com a população do que os representantes do Movimento. 
Estes, em seu discurso, mobilizavam a população para comparecerem a um ato que as centrais sindicais iriam organizar na semana seguinte ao ato que estava acontecendo. $O$ interessante do discurso deles era que sempre ressaltavam a importância do Movimento Não Pago e que este estaria presente na manifestação organizada por eles. Segundo Luiz Andrade, isso pode ser explicado através da visibilidade que o movimento conquistou depois dos Acorda Aracaju:

A gente ganhou certa evidência. Algumas organizaçôes perceberam que a gente ganhou certa evidência. Algumas organizações tentaram se utilizar dessa evidência que a gente tinha. Outras, não é porque a gente conseguiu articulações com algumas comunidades que a gente nunca teve, como Coqueiral, Tijuquinha, Bugio, que eram lugares que a gente nunca tinha chegado... A partir desses atos de junho, o pessoal passou a ter uma evidência no Não Pago, não só pelo debate de transporte, "pessoal tá com problema de saneamento", sei lá, "tá com problema de esgotamento sanitário", vamos falar com o Movimento Não Pago [...] (Caderno de Campo, Luiz Andrade, 31 de agosto de 2013).

Observa-se, a partir da narrativa acima, que o Movimento Não Pago passou a atuar também como mediador de causas que não eram vinculadas ao transporte público, como problemas vinculados à infraestrutura. Isso fez com que ele se inserisse em novos espaços e também disponibilizasse de mais recursos, uma vez que outras entidades viu o potencial de articulação e de representatividade que o Movimento estava tendo na cidade de Aracaju. Mas, além disso, nota-se que o capital escolar, militante e profissional de alguns membros do grupo possibilitou ao movimento uma maior legitimidade, tanto durante as manifestações do Acorda Aracaju, quanto em manifestações anteriores. Trabalhos como o de Bourdieu (2002), Coradini (1997) e Petrarca (2013), Oliveira (2008; 2009) analisam como atores sociais utilizam o título escolar como recurso que legitima uma determinada ação em determinados locais. A respeito disso, observou-se que o Movimento Não Pago tem um militante que é advogado e fica responsável por entrar com ações, fazer petições, defender os militantes quando são presos em alguma manifestação, etc., ou seja, esse tipo de recurso é mobilizado como estratégia de intervenção. Sendo assim, é um recurso importante tanto como forma de representação do movimento quanto para legitimar a causa defendida por ele.

As redes de apoiadores, os recursos mobilizados, sejam eles profissionais, pessoais, escolares ou materiais, são fatores que dizem respeito às condições de representação do Movimento. Como, por exemplo, de que forma os meios de comunicação os representa, como funciona o orçamento do movimento, em que medida as experiências pessoais dos membros do movimento (afetivas, familiares, de amizade, profissionais, etc.), coesão entre os membros do movimento influenciam nas dinâmicas de organização do movimento. Segundo Flávio Marcel, às vezes precisou abrir mão de estar com a família ou estar com a namorada para estar organizando algo do Movimento Não Pago, ou mesmo de ter atrasado seu curso na Universidade Federal de Sergipe, por conta da sua trajetória de militância. Ressaltou também que às vezes os militantes não têm passagem para ir às manifestações, porém quem tem mais condições ou quem tem carro dá carona ou paga a passagem daqueles que não têm, para conseguirem ir aos protestos realizados pelo movimento. Isso indica como o movimento se organiza e também o investimento pessoal que é feito principalmente pelas lideranças para organizar e manter o movimento atuante. 
Não a forma em si do movimento, mas a minha forma de organização gerou diversos prejuízos, assim, financeiros... De certa forma, desde quando entrei no movimento concretamente, me afastei de familiares. Pessoalmente, devido à rotina diferenciada. Assim, pessoalmente, você passa a ter menos tempo para as outras coisas, isso não acontece com todos os militantes, isso depende muito do período e do militante, eu, basicamente, tenho dificuldade em separar algumas questões e isso não acontece com todos... Eu coloco as questões que são necessárias para o movimento dar certo muito acima das questóes pessoais, isso às vezes atrapalha muito mesmo... Como por exemplo, ficar dois dias sem comer, ter 500 reais no mês e gastar 400 com o movimento, muito devido fazer aquilo acontecer por você entender que naquele momento tem que fazer acontecer. Se não fizer isso no momento, pode colocar tudo a perder, como aconteceu nos "Acordas", a gente sentou e viu que esse era o momento que a gente podia contribuir pra fazer uma diferença na sociedade, na nossa vida futuramente e na vida de todas as pessoas e a gente viu resultado. É meio que a gente tem de abdicar de uma vida particular para se dedicar àquilo... aí era 24 horas dormindo duas a três horas por dia, era estudando o dia todo, fiquei um mês sem ver minha família. São coisas assim que basicamente dependendo da época, como o crescimento foi muito grande e a gente não esperava, que repercutiu, pessoalmente afetou, mas quando a gente vai olhar a repercussão politicamente, como as pessoas me viam e me veem hoje, aí vem o lado positivo. (Caderno de campo, Flávio Marcel, 29 de agosto de 2013).

O relato de Flávio Marcel exemplifica como os atores tem que lidar com as questões pessoais, afetivas, familiares e com a militância; que o investimento na militância tem efeito sobre as outras esferas da vida e que a administração dessas diferentes esferas nem sempre são positivas. Um exemplo disso foram as manifestações de junho de 2013, onde houve um investimento pessoal dos militantes e uma organização dos movimentos sociais para que as manifestações acontecessem, mostrando que ao contrário do que acreditavam, os autores da Teoria do Comportamento Coletivo (Tarrow 2009) há uma organicidade e um investimento dos atores para realização das manifestações de massa. Além disso, tem a questão do compromisso ressaltado por outros militantes do Movimento Não Pago. Compromisso com a causa, com os outros militantes do movimento, com a população, todos estes aspectos foram ressaltados pelas lideranças ou pelos participantes como fundamentais para manter um movimento consolidado e com força representativa diante dos seus opositores.

A emergência e as condições de representação do Movimento Não Pago, portanto, está diretamente ligada às redes preexistentes feitas pelas suas lideranças em outros espaços de atuação, em que incluía partidos políticos, movimentos sociais, sindicatos, centrais sindicais, etc., aos repertórios organizacionais diferenciados, ou seja, uso de novos espaços como o virtual, um conjunto de ações que englobava não somente reuniões, cine debates, seminários de formação política, mas também passeatas, atos públicos, intervenções artísticas e dramáticas, além de panfletagem e abaixo-assinado. Está diretamente ligada também às experiências pessoais e investimento feito pelas suas lideranças, bem como aos recursos escolares, profissionais e de militância das mesmas, que foram acionados em momentos chaves da trajetória do Movimento para legitimá-lo, defendê-lo e representá-lo diante da população e de seus opositores. 


\section{Conclusão}

Este artigo examinou a emergência e as condições de representação do Movimento Não Pago entre o período de 2011 a 2013. Para tanto, foi necessário analisar dois movimentos que o antecederam: o Movimento Passe Livre e a Frente em Defesa da Mobilidade e do Transporte público. O primeiro atuou na cidade de Aracaju durante período de 2003 a 2010, o segundo foi organizado em 2010 e desarticulado no primeiro semestre de 2011. Os dois movimentos contribuíram para a emergência e a representação do Movimento Não Pago, sobretudo nos seguintes pontos: (1) construção de redes sociais e vínculos entre os militantes independentes; (2) estabeleceu um debate na cidade de Aracaju sobre mobilidade e transporte público, mobilizando principalmente trabalhadores, a juventude e os estudantes secundaristas e universitários; (3) difundiu determinados repertórios organizacionais, como seminários de formação política e intervenções artísticas; (4) promoveu uma articulação de diversas categorias da sociedade em torno das reivindicações da redução da tarifa, da tarifa zero, do passe livre para desempregados, entre outras, que mobilizava movimentos sociais, sindicatos, políticos partidários, etc. O Movimento Não Pago não surgiu somente a partir dessas condições prévias, que depois foram mobilizadas pelas lideranças do Movimento uma vez que faziam parte daqueles dois movimentos, mas de um conjunto de fatores que inclui tanto essas questões quanto as próprias experiências, interesses particulares, recursos profissionais, escolares e de militância, bem como as redes pessoais construídas em outros espaços de atuação pelos fundadores do Movimento.

Para tanto, foi necessário identificar como as lideranças do Movimento mobilizaram tais recursos e como estes permitiram que o movimento se organizasse de forma diferenciada do MPL e da Frente. Em relação a isso, notou-se que alguns fatores foram significativos como: múltiplo engajamento por parte de algumas lideranças durante toda sua trajetória de militância isso possibilitou ao Movimento diversificar suas formas de atuação tanto com relação aos seus opositores quando no recrutamento e na permanência dos militantes no movimento; os recursos profissionais e escolares de algumas lideranças permitiu ao movimento ganhar legitimidade e credibilidade diante dos seus opositores, quando estes fizeram um laudo técnico e divulgaram para toda população e para a Câmara de Vereadores de Aracaju. Além disso, o movimento contava com diversos profissionais como advogados, geógrafos, publicitários, jornalistas, etc., o que lhe permitia economizar financeiramente com determinados gastos de marketing e com a defesa de militantes presos; os eventos de protestos ocorridos em junho de 2013, que em Aracaju ficaram conhecidos como Acorda Aracaju possibilitou ao Movimento oportunidades políticas de ampliar suas redes e de recrutar novos militantes, bem como de uma maior visibilidade nos meios de comunicação televisionados locais que os representava como porta-voz das manifestações ocorridas nesse período na cidade.

Entende-se, portanto, a partir das análises de Mische (1996; 1997), Cefaï (2011) e de Clemens (2010), sobre identidade, repertórios organizacionais e redes sociais, que as experiências dos atores, os laços construídos previamente e os recursos mobilizados pelos atores, principalmente pelas lideranças do Movimento Não Pago, foram importantes tanto para as condições de representação do movimento quanto para seu surgimento e continuidade na cidade de Aracaju. Nesse sentido, é de suma importân- 
cia analisar as experiências de vida e as redes interpessoais dos atores. No presente caso, foi revelador analisar as experiências de militância, as redes interpessoais e os recursos profissionais e escolares de quatro lideranças do Movimento Não Pago, para compreender como eles se organizaram em torno da construção do Movimento e de sua representação.

\section{Adrielma Santos é doutoranda em Sociologia pelo Programa de Pós-Graduação em Sociologia (PPGS) da Universidade Federal de Sergipe (UFS)}

\section{REFERÊNCIAS BIBLIOGRÁFICAS}

ABRAMO, Helena; BRANCO, Pedro. (org.). 2005. Retratos da juventude brasileira: análises de uma pesquisa nacional. São Paulo: Fundação Perseu Abramo.

BORELLI, Silvia; ALVES, Rita. 2010. "Jovens urbanos, cultura e novas práticas políticas: acontecimentos estético-culturais e produção acadêmica brasileira”. Utopia y Praxis Latinoamericana [online]. 15 (50): 57-69.

BOURDIEU, Pierre. 2002. O poder simbólico. Rio de Janeiro: Bertrand Brasil.

CEFAÏ, Daniel. 2009. “Como nos mobilizamos? A contribuição de uma abordagem pragmatista para a sociologia da ação coletiva”. Revista Dilemas 2 (4): 11-44.

CORADINI, Odacir. 1997. "Origens Sociais e Princípios de Hierarquização Escolar: a formação de "intelectuais à brasileira”". Cadernos de Ciência Política 6:1-55.

CLEMENS, Elisabeth. 2010. "Repertórios organizacionais e mudança institucional: grupos de mulheres e a transformação da política nos EUA, 1890-1920”. Revista Brasileira de Ciência Política 3: 161-218.

GOHN, Maria da Glória. 1991. História dos movimentos e lutas sociais: a construção da cidadania dos brasileiros. São Paulo: Loyola.

. 2011. Teorias dos Movimentos Sociais-Paradigmas Clássicos e Contemporâneos. São Paulo: Edições Loyola. .2013. Sociologia dos Movimentos Sociais. São Paulo: Cortez.

. 2014. "A Sociedade Brasileira em Movimento: vozes das ruas e seus ecos políticos e sociais". Caderno CRH 27 (71): 431-441.

JUDENSNAIDER, Elena; LIMA, Luciana; ORTELLADO, Pablo; POMAR, Marcelo. Vinte centavos: a luta contra o aumento. São Paulo: Editora Veneta, 2013.

MARICATO, Hermínia. (org.).2013. Cidades Rebeldes: Passe Livre e as manifestações que tomaram as ruas do Brasil. São Paulo: Boitempo: Carta Maior.

MESQUITA, Marcos. 2003. "Movimento estudantil brasileiro: Práticas militantes na ótica dos Novos Movimentos Sociais”. Revista Crítica de Ciências Sociais 66: 117-149. 
.2008. "Cultura e política: A experiência dos coletivos de cultura no movimento estudantil". Revista Critica de Ciências Sociais 81: 179-207.

MISCHE, Ann. 1996. "Redes de jovens”. Revista Teoria \& Debate 31 (2): 23-29.

1997. “De estudantes a cidadãos, Redes de jovens e participação política”. Revista Brasileira de Educação 5: 134-150.

2008. Partisan publics: communication and contention across Brazilian youth networks.

Princeton: Princeton University Press.

MOISÉS, José Álvaro. 1981. “Protesto urbano e política: O quebra-quebra de 1947”. In: J.A. Moisés (org.). Cidade, povo e poder. Rio de Janeiro: Paz e Terra: 50-64.

OLIVEIRA, Wilson. 2008. "Gênese e redefinições do militantismo ambientalista no Brasil”. Dados Revista de Ciências Sociais. 51 (3): 751-777.

.2009. "Abertura política, militância múltipla e protestos públicos em defesa de causa ambientais". Caderno CERU. série 2.20 (1): 233-239.

.2010. "Posição de classe, redes sociais e carreiras militantes no estudo dos movimentos sociais”. Revista Brasileira de Ciência Politica. 3: 49 -77.

PETRARCA, Fernanda. 2013. "Esfera Política e processos de consolidação dos saberes profissionais". In: E. Seidl e I. G. Grill. (orgs.). As Ciências Sociais e os Espaços da Politica no Brasil. Rio de Janeiro: FGV: 103-140.

SANTOS, Adrielma. 2014. Movimento Não Pago - Emergência e Condições de Representação no Cenário Público de Aracaju/Se. Monografia. São Cristóvão, SE: Universidade Federal de Sergipe.

OLIVEIRA, Wilson. 2015. "Etnografia política das gramáticas de construção do transporte público e gratuito como uma causa pública”. In: 39 Encontro Anual da Anpocs, 2015, Caxambu. Anais... Caxambu/MG.

TARROW, Sidney. 2009. Opoder em movimento: movimentos sociais e confronto politico. Petrópolis. Rio de Janeiro: Vozes.

TILLY, Charles. 2010. "Movimentos Sociais Como Política”. Revista Brasileira de Ciência Política 3: 133-160.

SIQUEIRA, Paulo José. 21 dez. 1983. "Alves Fala Sobre Questão dos Ônibus e Não Agrada Comissão”. Jornal da Cidade, Aracaju/SE. Política local: 3.

SILVA, Marcelo. 2014. "\#vemprarua: o ciclo de protestos de 2013 como expressão de um novo padrão de mobilização contestatória?” In. A.D. Cattani (org.). \#protestos: análises das ciências sociais. Porto Alegre: Tomo Editorial. 


\section{MOVIMENTO NÃO PAGO: UMA LEITURA SOBRE A EMERGÊNCIA E AS CONDI- Çố de RepresentaÇão da CAUSA do TRANSPORTE PÚblico NA CIDAde DE ARACAJU/SE}

Resumo: O presente artigo examina as condições de representação e a emergência do Movimento Não Pago em torno das reivindicações no âmbito do transporte público e da mobilidade urbana entre o período de 2011 a 2013. Para tanto, foram analisados o Movimento Passe Livre (2003-2010) e a Frente em Defesa da Mobilidade e do Transporte Público (2010-2011). A abordagem utilizada focaliza nas redes sociais, nos repertórios organizacionais e nas experiências pessoais como construção de identidades dos atores. Os procedimentos metodológicos utilizados para a operacionalização deste trabalho foram, principalmente, análise documental, observação participante e entrevistas semiestruturadas. Conclui-se com a investigação, que o recurso escolar, profissional e militante, como também as redes preexistentes construídas pelas lideranças do Movimento em outros espaços de atuação, foram significativas tanto para a emergência do movimento quanto para suas condições de representação e o seu reconhecimento diante dos seus opositores, da mídia e da população de Aracaju.

Palavras-chave: Movimentos sociais; Movimento Não Pago; Repertórios organizacionais; Redes sociais; Tarifa zero.

\section{“WON"T PAY" MOVEMENT: A READING ABOUT THE EMERGENCY AND CONDI- TIONS OF REPRESENTATION OF THE CAUSE OF PUBLIC TRANSPORT IN THE CITY OF ARACAJU / SE}

Abstract: This article examines the conditions for representation and the emergence of the Won 't pay Movement around the claims in the public transport and urban mobility for the period from 2011 to 2013. Therefore, we analyzed the Movimento Passe Livre (2003-2010) and the front for the Defense of Mobility and Public Transport (2010-2011). The approach focuses on social networks, in the organizational repertoires and personal experiences as building identities of the actors. The methodological procedures used for the implementation of this work were mainly documentary analysis, participant observation and semi-structured interviews. It concludes with the investigation, the school resource, professional and activist, as well as existing networks built by Movement leaders in other areas of activity were significant both for the emergence of the movement and for their representation conditions and their recognition before his opponents, the media and the population of Aracaju.

Keywords: Social movements; Movimento Não Pago; organizational directories; social networks; zero tariff. 